Engineering, Technology and Techniques

Vol.59: e16161072, January-December 2016 http://dx.doi.org/10.1590/1678-4324-2016161072 ISSN 1678-4324 Online Edition

\title{
Mechanical Behavior of Concrete Modified by Replacement of Cement by Rice Husk Ash
}

\author{
M.M.Saravanan ${ }^{1} *$, M.Sivaraja ${ }^{2}$. \\ ${ }^{1}$ Department of Civil Engineering, Kongu Engineering College, Perundurai, Erode, Tamilnadu, India; ${ }^{2}$ N.S.N College of \\ Engineering and Technology, Karur, Tamilnadu, India.
}

\begin{abstract}
Construction industry is in need of lump sum quantities of materials which has increased both their demand and price. The use of large quantities of cement leads to increasing $\mathrm{CO}_{2}$ emission and as a consequence, the greenhouse effect. Consumption of wastes and byproducts from various sources in the manufacture of concrete has gained a great deal of importance in present days. Various researches are currently being conducted concerning the use of such products in concrete. RHA is a carbon neutral green product. Lots of ways are being thought of for disposing them by making commercial use of this. Rice husk ash is a good super-pozzolan which can be used to make special concrete mixes. The rice husk ash has been taken for this present study due to its easy availability and effective pozzolonic properties that are expected to improve the mechanical strength properties of concrete. Concrete specimens were made for evaluation of Compressive, Split Tensile, Flexural strength and Stress-Strain Behavior of concrete. The tests were conducted at the age of 7 and 28 days. Generally all mixes containing RHA achieved better properties than the conventional mix without RHA. By the experimental investigation the recommendation is given for using optimum percentage of RHA in concrete.
\end{abstract}

Key words: husk ash; strain; compressive; split tensile; flexural.

\footnotetext{
*Author for correspondence: saromms@gmail.com
} 


\section{INTRODUCTION}

Concrete is the largest building material used by the construction industry. Concrete is basically made of both fine and coarse aggregates, binding by cement. Each one of these constituents of concrete hasn't a positive environmental impact and gives rise to different sustainability issues. The recent concrete construction practice is unsustainable even not only it consumes enormous quantities of stones, sand and water, but also one billion tons of cement a year, which is not an environment friendly material. For manufacturing of cement large amount of energy is needed and also $8 \%$ of carbon dioxide is released to the atmosphere during cement production. In fact, many byproducts and solid wastes can be used in concrete mixes as admixtures or aggregates or cement by partial or full replacement, depending on their physical and chemical characterization, if adequately treated. Thus cement is replaced by partial amount of RHA as a mineral admixture. Several materials are used to manufacture good quality concrete. It is important to know the properties of cement, aggregate, and water, as they impart strength and durability to concrete of all the materials that influence the behavior of concrete, cement is the most important constituent, because it is used to bind the sand and aggregate together and it resists atmospheric action. Durability problems arise during the service life of a concrete structure. This actually is a result of improper design, execution or specification at the time of tendering for the work. There is no material which is $100 \%$ resistant to chemical action and deterioration due to physical action such as abrasion or impact. However under normal conditions, good quality of concrete has a long life.

\section{MATERIALS USED}

\section{Cement}

Cement is the most important ingredient in concrete. Ordinary Portland Cement (OPC) of 43 Grade confirming to IS: 12269 - 1987 is used for the entire investigation. The specific gravity of Ordinary Portland cement is 3.15.

\section{Fine Aggregate}

Depending upon the particle size distribution, locally available river sand confirming to Zone II of Table 4 of IS 383-1970 was used in the casting process. The specific gravity of the sand is found to be 2.65 . Fine aggregate used should be properly graded to give minimum void ratio and should be free from deleterious materials like clay, silt content and chloride contamination etc.

\section{Coarse Aggregate}

The coarse aggregate is the strongest and the least porous component of concrete. It is also a chemically stable material. The blue granite stone was used as a coarse aggregate for this work. The nominal size of the aggregate is $20 \mathrm{~mm}$. The specific gravity of the coarse aggregate is found to be 2.78 . By restricting the maximum size of aggregate and also by creating the transition zone stronger by usage of mineral admixtures such as rice husk ash, the cement concrete becomes more homogenous and there is a marked enhancement in the strength properties as well as durability characteristics of concrete.

\section{Water}

Water is a crucial and important ingredient of the concrete as it actively participates in the chemical reaction with cement and results in hardening of the 
concrete. The water used in this study was potable water. The potable water used was confirming to the requirements of IS 456-2000.

\section{Rice Husk Ash (RHA)}

Rice husk ash is obtained by burning of the rice husk obtained from rice mills. Calcium hydroxide accounts for up to $25 \%$ of the hydrated cement and calcium hydroxide does not contribute to the concrete's strength or durability. Like other pozzolans, RHA reacts with the calcium hydroxide (lime) by-products produced during cement hydration to produce additional cementing compound, which is responsible for holding the concrete together. It is very fine, highly reactive and gives fresh concrete a creamy and non sticky texture that makes finishing easier. RHA improves the compressive strength of concrete, makes finishing easier, reduces efflorescence and also mitigates alkali, silica reaction.

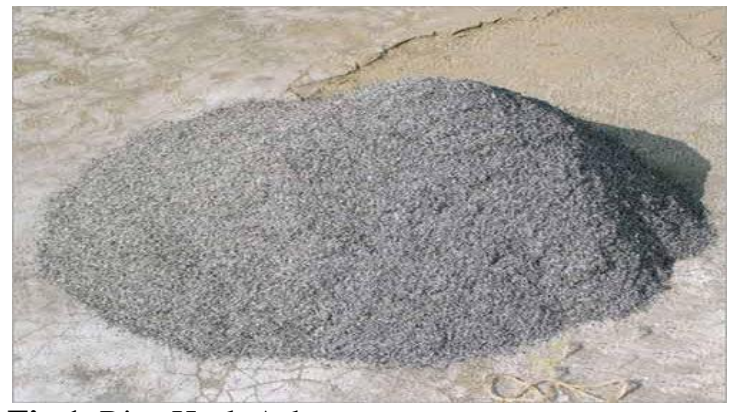

Fig 1. Rice Husk Ash

It is a pozzolan material consisting of alumina and silica. So it can be used in the concrete to replacement of Ordinary Portland Cement. The chemical composition of RHA includes Sand or Silica, Calcium Oxide $(\mathrm{CaO})$, Magnesium Oxide $(\mathrm{MgO})$, Iron Oxide $\left(\mathrm{Fe}_{2} \mathrm{O}_{3}\right)$, Aluminium oxide $\left(\mathrm{Al}_{2} \mathrm{O}_{3}\right)$, Sodium Oxide $\left(\mathrm{Na}_{2} \mathrm{O}\right)$ and Potassium Oxide. Their percentage varies at different temperatures. The physical properties of RHA are given in Table 1.

Table 1 Physical Properties of RHA

\begin{tabular}{|l|l|}
\hline Color & Grey \\
\hline Appearance & Powder form \\
\hline Specific Gravity & 2.14 \\
\hline Normal Consistency & $30 \%$ \\
\hline
\end{tabular}

\section{Replacement of cement by RHA}

The advantage of replacing some of the cement with RHA rather than addition of RHA to the mix is that any existing color formulas or mix designs won't change, or slightly change. This is because the dosage of pigments and super plasticizers are added based on the cement content in the concrete. It is ok to simply add RHA to an existing mix, but it is important to realize that the total equivalent cement content will increase. This will affect not only the addition pigment and admixture dosages but also the water to cement ratio, a critical factor in mix design. RHA is compatible with most of the concrete admixtures, such as super plasticizers, retarders, accelerators, etc. The results demonstrate that $15 \%$ replacement of cement with RHA is effective. The addition of more than $20 \%$ RHA has a detrimental effect on strength and efflorescence. 


\section{EXPERIMENTATION}

\section{Concrete Mix Proportions}

The M30 mixes were designated in accordance with IS $10262-1982$. Based on the results, the proportions M30 was considered. Concrete mix with w/c ratio of 0.45 was prepared. The details of mix proportions are given in Table 2 for $1 \mathrm{~m}^{3}$ of concrete.

Table 2 Materials required for $1 \mathrm{~m}^{3}$ of Concrete $\left(\mathrm{kg} / \mathrm{m}^{3}\right)$

\begin{tabular}{|c|c|c|c|c|}
\hline Grade & Cement & FA & CA & Water \\
\hline M30 & 438 & 686.24 & 1126 & 197 \\
\hline
\end{tabular}

In this work, the percentage replacement of RHA was $10 \%, 20 \%$ and $30 \%$ of the total weight of cement.

\section{Casting of Specimen}

The experimental investigation was carried out by casting cubes; cylinder and prism for both the conventional concrete mix and RHA replaced concrete. The mixing procedures are as follows: Initially Cement, Sand and RHA were taken in the required quantities and were mixed dry and kept separately. Then, coarse aggregate and the prepared dry mix were kept in three layers and approximate amount of water was sprinkled on each layer and mixed thoroughly. Mixing procedure was extremely tedious to the formation of lumps. Concrete was thoroughly mixed and compacted. The cubes of size $150 \mathrm{~mm}$ x $150 \mathrm{~mm} \times 150 \mathrm{~mm}$ were cast for testing the compressive strength of concrete and cylinders of diameter $150 \mathrm{~mm}$ and height $300 \mathrm{~mm}$ were cast for the split tensile strength. For flexural strength test, prisms of size $500 \mathrm{~mm}$ x $100 \mathrm{~mm}$ x $100 \mathrm{~mm}$ were cast. Samples for different percentages of concrete were casted. The number of specimens cast for the present study is listed in Table 3 .

Table 3 Details of Test Specimens

\begin{tabular}{|c|c|c|}
\hline Type of specimen & No. of specimens & Size of specimens \\
\hline Cube & 20 & $150 \mathrm{~mm} \times 150 \mathrm{~mm} \times 150 \mathrm{~mm}$ \\
\hline Cylinder & 20 & $150 \mathrm{~mm}$ diameter and $300 \mathrm{~mm}$ height \\
\hline Prism & 20 & $500 \mathrm{~mm} \times 100 \mathrm{~mm} \times 100 \mathrm{~mm}$ \\
\hline
\end{tabular}

\section{Curing of Specimens}

The specimens were remolded 24 hours after casting and the specimens were kept inside a water tub containing potable water and allowed for curing. They were taken out from the curing tank after 7 days and 28 days and were dried for 1 day in shadow before testing. The specimens were tested in saturated condition after wiping out the surface moisture from the specimen.

\section{TEST RESULTS AND DISCUSSION}

\section{Compressive Strength}

The cubes of size $150 \mathrm{~mm} \times 150 \mathrm{~mm} \times 150 \mathrm{~mm}$ were employed for testing the compressive strength of concrete. All the cubes of Conventional Concrete and RHA replaced Concrete were tested in a HEICO Compression Testing Machine with references of IS: $516-1959$ at an age of 7 days and 28 days. The test results of the Compressive Strength were given in graphically in Fig.2 


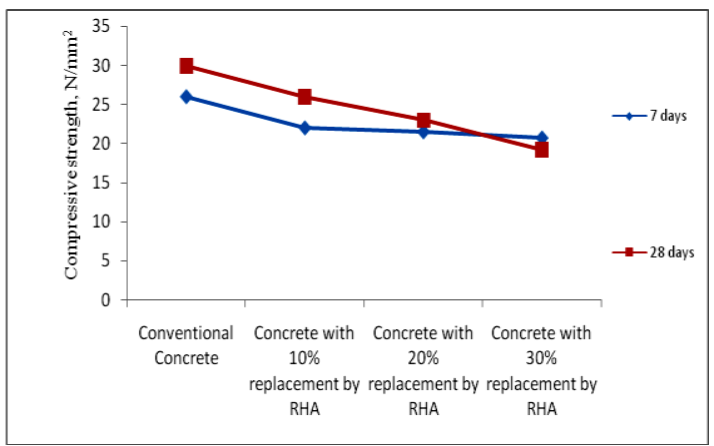

Fig. 2 Compressive Strength at 7 days and 28 days

\section{Split Tensile Strength}

The tensile strength characteristics of concrete are of considerable importance and split tensile test is a simple and reliable method for measuring the tensile strength of concrete. Splitting tensile tests were carried out on cylindrical specimens of diameter $150 \mathrm{~mm}$ and height $300 \mathrm{~mm}$ at an age of 7 days and 28 days using HEICO Compression Testing Machine of capacity 400 tonnes confirming to IS: 5816 - 1970. The test results were given in Fig.3.

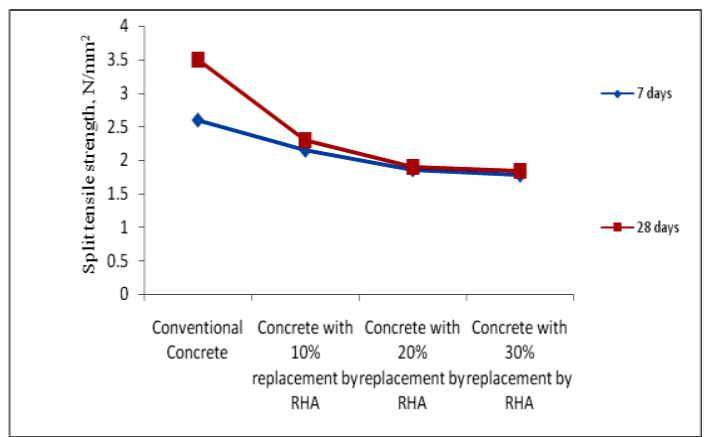

Fig.3 Split Tensile Strength at 7 days and 28 days

\section{Flexural Strength}

The flexural strength tests were carried out in Universal Testing Machine by Two Point loading method with the guidelines given by IS: $516-1959$. The specimens were of size $500 \mathrm{~mm} \times 100 \mathrm{~mm} \times 100 \mathrm{~mm}$. The variation of flexural strength is presented graphically in Fig.4.

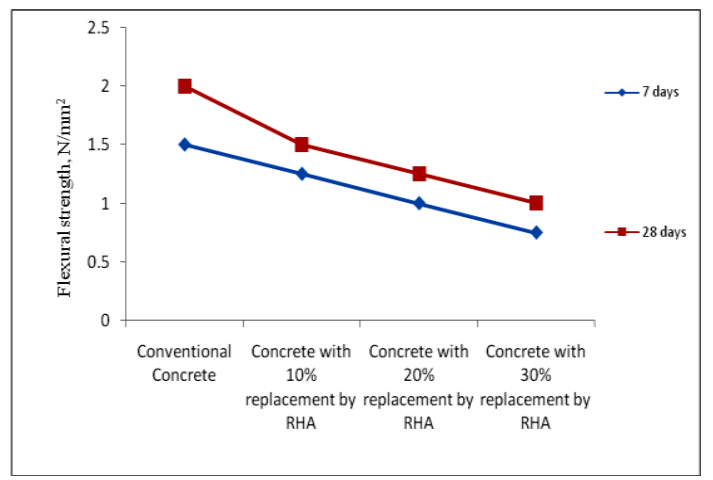

Fig.4 Flexural Strength at 7 days and 28 days

\section{Stress - Strain Behavior of Concrete}

The stress strain values for $10 \%, 20 \%, 30 \%$ replacement by RHA were given in Table 4, Table 5 and Table 6 respectively. The stress strain curves of concrete with 
10\%, 20\% and 30\% replacement by RHA were shown in Fig.5, Fig.6 and Fig.7 respectively.

Table 4 Stress Strain Values for 10\% Replacement of RHA

\begin{tabular}{|c|c|c|c|c|}
\hline Load $(\mathrm{N})$ & $\begin{array}{c}\text { Area } \\
\left(\mathrm{mm}^{2}\right)\end{array}$ & $\begin{array}{c}\text { Deflection } \\
(\mathrm{mm})\end{array}$ & $\begin{array}{c}\text { Stress } \\
\left(\mathrm{N} / \mathrm{mm}^{2}\right)\end{array}$ & Strain \\
\hline 0 & 17663 & 0 & 0 & 0 \\
\hline 10000 & 17663 & 0 & 0.566 & 0 \\
\hline 20000 & 17663 & 0 & 1.132 & 0 \\
\hline 30000 & 17663 & 0 & 1.698 & 0 \\
\hline 40000 & 17663 & 0 & 2.264 & 0 \\
\hline 50000 & 17663 & 0.012 & 2.830 & $8 \mathrm{E}-05$ \\
\hline 60000 & 17663 & 0.026 & 3.397 & 0.0002 \\
\hline 70000 & 17663 & 0.034 & 3.963 & 0.0002 \\
\hline 80000 & 17663 & 0.044 & 4.529 & 0.0003 \\
\hline 90000 & 17663 & 0.056 & 5.095 & 0.0004 \\
\hline 100000 & 17663 & 0.072 & 5.661 & 0.0005 \\
\hline 110000 & 17663 & 0.08 & 6.227 & 0.0005 \\
\hline 120000 & 17663 & 0.094 & 6.79 & 0.0006 \\
\hline 130000 & 17663 & 0.11 & 7.360 & 0.0007 \\
\hline 140000 & 17663 & 0.156 & 7.926 & 0.001 \\
\hline 150000 & 17663 & 0.218 & 8.492 & 0.0015 \\
\hline
\end{tabular}

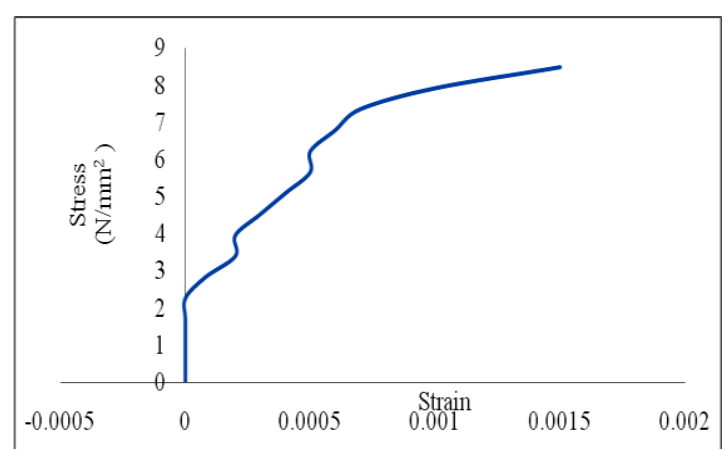

Fig.5 Stress Strain curve for $10 \%$ replacement by RHA

Table 5 Stress Strain Values for 20\% Replacement of RHA

\begin{tabular}{|c|c|c|c|c|}
\hline $\begin{array}{c}\text { Load } \\
(\mathrm{N})\end{array}$ & $\begin{array}{c}\text { Area } \\
\left(\mathrm{m}^{2}\right)\end{array}$ & $\begin{array}{c}\text { Deflection } \\
(\mathrm{mm})\end{array}$ & $\begin{array}{c}\text { Stress } \\
\left(\mathrm{N} / \mathrm{mm}^{2}\right)\end{array}$ & Strain \\
\hline 0 & 17663 & 0 & 0 & 0 \\
\hline 10000 & 17663 & 0 & 0.566 & 0 \\
\hline 20000 & 17663 & 0 & 1.132 & 0 \\
\hline 30000 & 17663 & 0 & 1.698 & 0 \\
\hline 40000 & 17663 & 0 & 2.264 & 0 \\
\hline 50000 & 17663 & 0.01 & 2.830 & 0.0001 \\
\hline 60000 & 17663 & 0.03 & 3.397 & 0.0002 \\
\hline 70000 & 17663 & 0.03 & 3.963 & 0.0003 \\
\hline 80000 & 17663 & 0.05 & 4.529 & 0.0003 \\
\hline 90000 & 17663 & 0.06 & 5.095 & 0.0005 \\
\hline
\end{tabular}


Concrete Modified by Replacement of Cement

\begin{tabular}{|c|c|c|c|c|}
\hline 100000 & 17663 & 0.08 & 5.661 & 0.0006 \\
\hline 110000 & 17663 & 0.1 & 6.227 & 0.0007 \\
\hline 120000 & 17663 & 0.12 & 6.794 & 0.0008 \\
\hline 130000 & 17663 & 0.15 & 7.360 & 0.001 \\
\hline 140000 & 17663 & 0.2 & 7.926 & 0.0013 \\
\hline 150000 & 17663 & 0.27 & 8.492 & 0.0018 \\
\hline
\end{tabular}

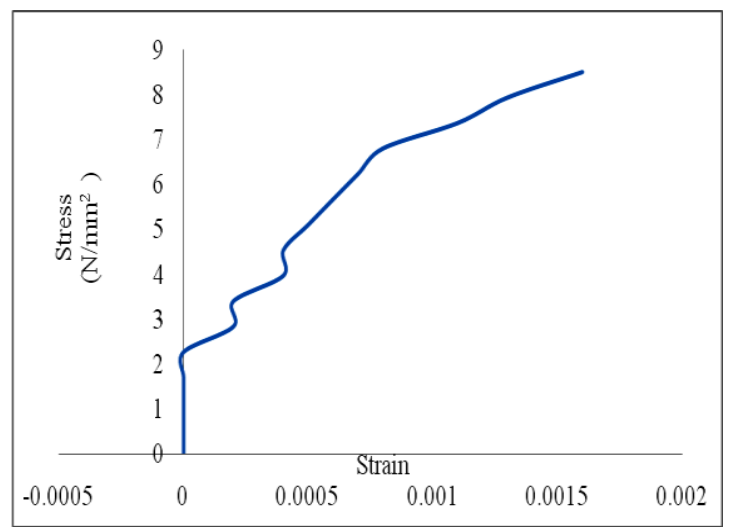

Fig.6 Stress - Strain curve for $20 \%$ replacement by RHA

Table 6 Stress Strain Values for 30\% Replacement of RHA

\begin{tabular}{|c|c|c|c|c|}
\hline $\begin{array}{c}\text { Load } \\
(\mathrm{N})\end{array}$ & $\begin{array}{c}\text { Area } \\
\left(\mathrm{mm}^{2}\right)\end{array}$ & $\begin{array}{c}\text { Deflection } \\
(\mathrm{mm})\end{array}$ & $\begin{array}{c}\text { Stress } \\
\left(\mathrm{N} / \mathrm{mm}^{2}\right)\end{array}$ & Strain \\
\hline 0 & 17663 & 0 & 0 & 0 \\
\hline 10000 & 17663 & 0 & 0.566 & 0 \\
\hline 20000 & 17663 & 0 & 1.132 & 0 \\
\hline 30000 & 17663 & 0 & 1.698 & 0 \\
\hline 40000 & 17663 & 0 & 2.264 & 0 \\
\hline 50000 & 17663 & 0.02 & 2.830 & 0.0002 \\
\hline 60000 & 17663 & 0.03 & 3.397 & 0.0002 \\
\hline 70000 & 17663 & 0.05 & 3.963 & 0.0004 \\
\hline 80000 & 17663 & 0.06 & 4.529 & 0.0004 \\
\hline 90000 & 17663 & 0.07 & 5.095 & 0.0005 \\
\hline 100000 & 17663 & 0.08 & 5.661 & 0.0006 \\
\hline 110000 & 17663 & 0.09 & 6.227 & 0.0007 \\
\hline 120000 & 17663 & 0.12 & 6.794 & 0.0008 \\
\hline 130000 & 17663 & 0.16 & 7.360 & 0.0011 \\
\hline 140000 & 17663 & 0.19 & 7.926 & 0.0013 \\
\hline 150000 & 17663 & 0.24 & 8.492 & 0.0016 \\
\hline
\end{tabular}

Braz. Arch. Biol. Technol. v.59: e16161072 Jan/Dec 2016 Spec Iss 2 


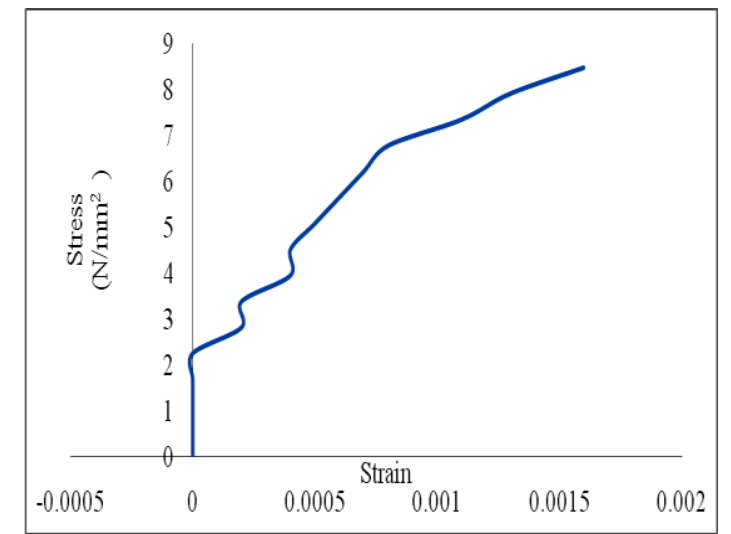

Fig.7 Stress - Strain curve for 30\% replacement by RHA

\section{Micro Structural Behavior of Rice Husk Ash}

The micro structure of cement replaced by Rice husk ash was observed and the micro structural behavior was reported. The composition of chemical elements were also observed and discussed. The scanning electron microscope (SEM) analysis and EDAX analysis were carried out on powder samples prepared from burning of rice husk. The results obtained in SEM and EDAX analysis were shown in Fig. 8 and Fig.9 and were discussed in the following section.

Table 7 Result of Weight Percentage of Elements

\begin{tabular}{|c|c|}
\hline \multirow{2}{*}{ Element } & Weight Percentage \\
\cline { 2 - 2 } & RHA \\
\hline $\mathrm{O}$ & 55.86 \\
\hline $\mathrm{Mg}$ & 1.57 \\
\hline $\mathrm{Si}$ & 35.37 \\
\hline $\mathrm{P}$ & 3.53 \\
\hline $\mathrm{K}$ & 2.42 \\
\hline $\mathrm{Ca}$ & 1.26 \\
\hline Total & 100.00 \\
\hline
\end{tabular}

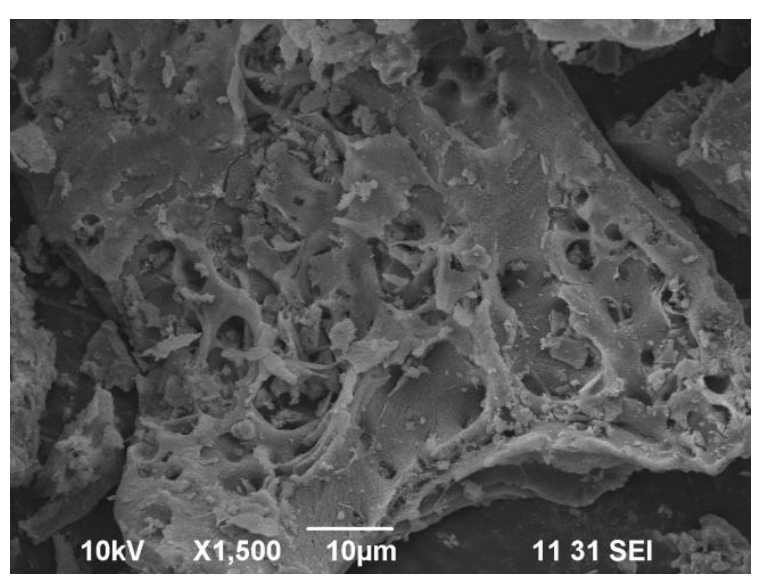

Fig.8 SEM image of Rice husk ash 
Concrete Modified by Replacement of Cement

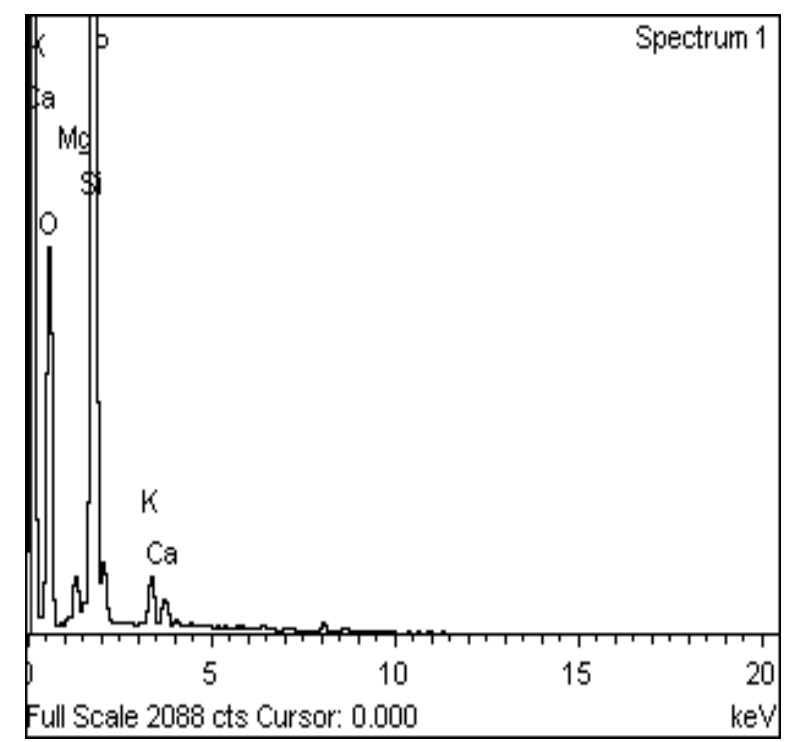

Fig.9 EDAX Spectrum of Rice husk ash

In Fig. 8 shows the micrograph of rice husk ash, it consists of fine particles, which appears to have agglomerated large group of particles. The extent of coverage is substantial but not enough materials formed to create a continuous film on the surface of the particle. Some region shows the traces of no hydration products and absence of deposition of hydration products. This shows that due to abundance of hydration products the appearance has changed from small isolated particles to tangled web of flake like crystals. The hydration products consist of a mixture of phases as it's typical for Portland cement. The shows that the SEM analysis of Rice husk ash particle has been covered in a continuous pattern of very small particles were identified. The EDAX graphs were shown in Fig.9 and the weight percentage of elements are shown in Table 7. This result shows that Mg content increases in rice husk ash and also the graphs shows that the Silica content increases at the maximum level.

\section{CONCLUSIONS}

Experimental investigations were carried out for concrete mixes with 10\%, 20\% and 30\% replacement of cement by RHA to find the mechanical properties of concrete with w/c ratio 0.45 . The test results show clearly that concrete with RHA shows significant effects on the mechanical properties of concrete. Out of all the mixes considered, Concrete with $10 \%$ and $20 \%$ replacement of cement by RHA was found to be optimum. From the basic study to utilize RHA as cement replacement, the following conclusions are arrived.

1. The flexural strength value is more for $20 \%$ replacement of RHA.

2. From the examination on RHA used for cement replacement it can be inferred that the normal consistency of cement defer according to the percentage of RHA.

3. RHA incorporated cement, it can be inferred that RHA acts as retarder \& increases the initial setting time of the cement.

4. It is noticed from the analysis of the compressive strength results that as the replacement percentage of RHA increases, the compressive strength decreases due to low pozzolanic property of RHA.

5. The Scanning Electron Microscopy images show that the Rice husk ash is creating a very denser formation. 
6. From the EDAX analysis it was concluded that the content of Silica is the maximum level and also a small variation in $\mathrm{Ca}$ content. So Rice husk ash is a good pozzolans material to replace by cement at certain percentage.

\section{REFERENCES}

1. Akindehinde Ayotunde Akindahunsi and Oluwotosin Alade, "Exploiting the potentials of rice husk ash as supplement in cement for construction in nigeria", International Journal of Concrete Structures and Materials, 2010, Vol.4, No.1, pp. 3-8.

2. Ali Nazari and Shadi Riahi, "The effects of TiO2 nanoparticles on properties of binary blended concrete", Journal of Composite Materials, 2010, Vol. 45, Issue 11, pp. 1181-1188.

3. P. S. V. R. Subrahmanyam G. Narsaraju and B. Srinivasa Rao, “ Effect of rice husk ash and fly ash reinforcements on microstructure and mechanical properties of aluminium alloy (AlSi10Mg) matrix composites", International Journal of Advanced Science and Technology, 2015, Vol.76, pp.1-8.

4. Aseel B. Al-Zubaidi Ahmed A.AL-Tabbakh, Raghad U.Abass and Eman A.Hameed, "Study on mechanical behaviors rice husk ash and carrot powders as mortar for cement replacement", International Journal of Innovative Science, Engineering \& Technology, 2015, Vol. 2, Issue 3, pp.39-44.

5. B.Suja, T.Jenies and V. Jaganathan, "A study on characteristics strength of hybrid fibre reinforced self compacting concrete incorporating rice husk ash", Journal of Mechanical and Civil Engineering, 2016, Vol. 2, Issue 2, pp.10 - 17.

6. Elba Helen George B. Bhuvaneshwari, G. S. Palani, P. Eapen Sakaria, and Nagesh R. Iyer, "Effect of basalt fibre on mechanical properties of concrete containing fly ash and metakaolin ", International Journal of Innovative Research in Science, Engineering and Technology”, 2014, Vol. 3, Special Issue 5, pp. 444-451.

7. Farook Adam Jeyashelly Andas and Ismail Ab. Rahman "The synthesis and characterization of cobalt-rice husk silica nanoparticles", The Open Colloid Science Journal, 2011, Vol. 4, pp. 12-18.

8. Ghassan Abood Habeeb Hilmi Bin Mahmud, "Study on properties of rice husk ash and its use as cement replacement material", Materials Research, Vol. 13, Issue 2, pp. 185-190.

9. IS- 10262 (2009), "Indian Standard Code for Concrete Mix Proportioning Guidelines (First Revision)”, Bureau of Indian Standards, New Delhi.

10. IS- 383: 1970, "Indian Standard Code for Specification for Fine and Coarse Aggregate", Bureau of Indian Standards, New Delhi.

11. J. Babu Rao P. Narayanaswami and K. Siva Prasad, "Thermal stability of nano structured fly ash synthesized by high energy ball milling”, International Journal of Engineering, Science and Technology, 2010, Vol. 2, No. 5, pp. 284-299.

12. Jyotiprakash Nayak and Japes Bera, "A simple method for production of humidity indicating silica Gel from rice husk ash", Journal of Metals, Materials and Minerals, 2009, Vol.19, No.2, pp.15-19. 
13. Lee Bong Chun et al, "A study on the fundamental properties of concrete incorporating RHA and microsilica", The 3rd ACF International Conference-ACF/VCA, 2008, Korea.

14. M. Murat, C. Comel, "Hydration reaction and hardening of calcined clays and related minerals Iii and Influence of calcination process of kaolinite on mechanical strengths of hardened RHA and microsilica", Cement and Concrete Research, 1983, Vol.13, pp 631-637.

15. Mullick A.K.,"Durability advantage of concrete cast against controlled permeability formwork liner", Civil Engineering \& Construction Review, 2008, January issue, pp34-46.

16. Mustapha Abdulhadi, "A comparative study of basalt and polypropylene fibers reinforced concrete on compressive and tensile behavior", International Journal of Engineering Trends and Technology, 2014, Vol. 9, Issue 6, pp.295 - 300.

17. Piyawan Prawingwong Chaiyan Chaiya, Prasert Reubroycharoen and Chanatip Samart, "Utilization of rice husk ash silica in controlled releasing application", Journal of Metals, Materials and Minerals, 2009, Vol.19, No.2, pp.61-65.

18. Rao Sudarsana. H, et al, "Durability studies on RHA and microsilica based highperformance-concrete", International Journal of Advanced Scientific Research and Technology, 2012, Vol.2, Issue.2, pp204-211.

19. Sabir B.B, Wild S., Bai J., "RHA and microsilica and calcined clays as pozzolans for concrete: a review", Cement and Concrete Composites, 2001, Vol.23, pp. 441-454.

20. Shetty M. S., (2006), Concrete Technology, S.Chand and Company Ltd, New Delhi.

21. Srinivasan Karunanithi et al., "Flexural toughness properties of reinforced steel fibre incorporated alkali activated slag concrete", Advances in Civil Engineering, 2014, Vol. 2014, Article ID 719436, pp.1-12.

22. Tzong-Horng Liou and Chun-Chen Yang, "Synthesis and surface characteristics of nanosilica produced from alkali-extracted rice husk ash", Materials Science and Engineering B, 2011, Vol. 176, pp. 521-529.

23. Qing Y et al. "Influence of nano-SiO2 addition on properties of hardened cement paste as compared with silica fume", Construction and Building Materials, 2007, Vol. 21, pp. 539-545.

24. Umesh Sharma et al., "Use of micro-silica as additive to concrete-state of art", International Journal of Civil Engineering Research, 2014, Vol. 5, Number 1, pp. 9-12.

25. Verma Ajayet al., "Effect of micro silica on the strength of concrete with ordinary portland cement", Research Journal of Engineering Sciences, 2012, Vol. 1, Issue 3, pp. 1-4.

Received: February 03, 2016; Accepted: July 14, 2016 